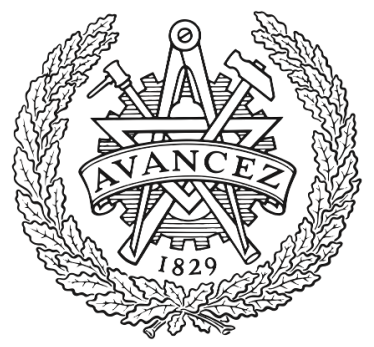

CHALMERS

UNIVERSITY OF TECHNOLOGY

\title{
A numerical and experimental study of a pavement solar collector for the northern hemisphere
}

Downloaded from: https://research.chalmers.se, 2023-04-26 13:45 UTC

Citation for the original published paper (version of record):

Johnsson, J., Adl-Zarrabi, B. (2020). A numerical and experimental study of a pavement solar collector for the northern hemisphere. Applied Energy, 260.

http://dx.doi.org/10.1016/j.apenergy.2019.114286

N.B. When citing this work, cite the original published paper. 


\title{
A numerical and experimental study of a pavement solar collector for the northern hemisphere
}

\author{
Josef Johnsson*, Bijan Adl-Zarrabi \\ Chalmers University of Technology, Sven Hultins gata 6, Gothenburg, Sweden
}

\section{H I G H L I G H T S}

- Field tests of a pavement solar collector connected to boreholes.

- Highly efficient pavement solar collector with efficiency of $42 \%$.

- Numerical investigation of the effect of albedo, flow rate and pipe spacing.

- First time report of surface condensation on pavement solar collectors.

\section{A R T I C L E I N F O}

\section{Keywords:}

Pavement solar collector

PSC

HHP

Hydronic Heated Pavements

Borehole

Albedo

2000 MSC:

00-01

99-00

\begin{abstract}
A B S T R A C T
Solar energy is a renewable energy source that is globally available. To utilise this type of energy, novel technologies are developed across the globe. Among these, the pavement solar collector (PSC) technology has a considerable potential. A PSC consist of pipes, that are embedded into the upper pavement layers through which fluid is circulated. Solar radiation heats the pavement surface, and the absorbed heat is transferred to the circulating fluid. One applications is to use the heat for recharging shallow geothermal boreholes with solar energy during summer, thereby reducing the electricity consumption of ground source heat pumps during winter. In Scandinavia, however, the knowledge on the PSC application is limited. The Swedish transport administration has therefore established a field station to gain more insight on the PSC in Scandinavia. This paper reports the findings of the investigation from the summer of 2018 and how the efficiency of the PSC is affected by altering the albedo, fluid flow rate, and pipe spacing. The measured harvested energy is $245 \mathrm{kWh} / \mathrm{m}^{2}$ with a solar efficiency of $42 \%$. It is found that by altering the albedo and flow rate, the efficiency could be enhanced by up to $49 \%$. This high efficiency achieved in this study is dependent on the short pipe spacing of $5 \mathrm{~cm}$ and results in surface condensation on several occasions. Condensation on PSC has not been reported previously but should not pose a risk to road traffic because surface temperatures are above freezing.
\end{abstract}

\section{Introduction}

The United Nations Sustainable Development Goal SDG 7 states that man should ensure access to affordable, reliable and modern energy for all. At present, approximately $30 \%$ of the global energy demand is used for cooling and heating buildings.

The energy requirement of the building sector represents a large part of the global energy demand. To deal with global warming and realise SDG 7 [1], this sector must reduce the usage of fossil fuels by $75 \%$ until 2060 . This can be achieved by replacing such fuels with renewable alternatives, such as solar energy, which is a globally available renewable energy source. A novel approach is the utilisation of rural and urban roads for energy harvesting. Harvested energy can either be in the form of electrical energy or thermal energy. Electrical energy can be harvested by supplementing the pavement surface with photovoltaic solar panels [2], piezoelectric devices [3], or thermoelectric devices [4]. The pavement solar collector (PSC) is an alternative for harvesting thermal energy according to Ahmad et al. [5]. Common PSCs are built by incorporating a pipe system into the upper layers of road constructions, as shown in Fig. 1. During sunny days, solar radiation is absorbed by the pavement surface, and the absorbed energy is transferred to the fluid within the pipes and is either utilised for heating or stored for later use [6].

An additional advantage that the PSC affords is the reduction in pavement temperatures. Reduced temperatures extend the service life of pavements especially asphalt pavements because the permanent

\footnotetext{
* Corresponding author.

E-mail address: Josefj@chalmers.se (J. Johnsson).
} 

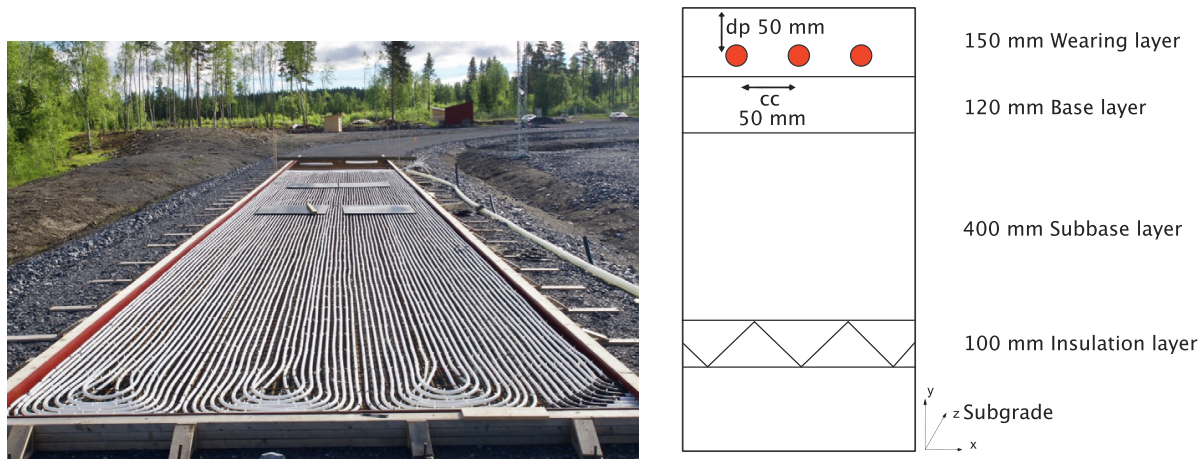

(a) Pavement solar collector before casting of (b) Road section with materials and posiconcrete

tion of pipes.

Fig. 1. Construction of an pavement solar collector near Östersund, Sweden.

deformations induced by rutting are decreased [7]. Concrete pavements similarly benefit from lower temperatures because smaller temperature fluctuations means lower thermal stresses on concrete slabs [8]. Another advantage of lowering road surface temperatures is that it can decrease the effect of urban heat islands (UHI) [9]. The UHI is referred to as areas of a city that are considerably warmer than surrounding areas. The UHI results in thermal discomfort in buildings and increases the energy demand of air conditioning.

The use of PSC is also suggested for snow removal in winter by supplying heat to the pavement surface. This is regarded as an alternative that can reduce the environmental impact of winter road maintenance. When the PSC is utilised for snow melting, it is commonly called hydronic heated pavement (HHP) $[10,11]$.

A number of experimental studies have demonstrated the possibilities of harvesting energy from pavement solar collectors. Loomans et al. [12] investigated a pavement collector in the Netherlands during a summer with an average air temperature of $14^{\circ} \mathrm{C}$. They found that the energy efficiency was approximately $30 \%$, i.e., approximately $30 \%$ of the incoming solar heat on the pavement surface could be harvested. Furthermore, the fluid temperature in pipes was approximately $20{ }^{\circ} \mathrm{C}$ during energy harvesting. The solar efficiency from Loomans et al. [12] was used by the authors to estimate the harvesting potential of PSC in the Scandinavian context. It was found that approximately $140 \mathrm{kWh} /$ $\mathrm{m}^{2}$ could be harvested [13].

Baetens et al. [14] indicated the possibility of utilising the PSC as prosumers in district heating networks with ultra-low temperature. They observed that the fluid temperature over a 200-m long pipe could reach $28{ }^{\circ} \mathrm{C}$, which is found to be insufficient for ultra-low district heating. A heat pump is hence necessary to further increase the temperature. The combination of a PSC and a heat pump is a concept that should be explored further.

Guldentops et al. [15] developed a finite element model for the PSC and validated the model by an experimental set-up. Based on simulations, it was found that the solar efficiency of the PSC varied from $15 \%$ to $20 \%$ when different solar absorptivities, thermal conductivities, and pipe depths were used. The solar efficiency was enhanced by higher solar absorptivity, higher thermal conductivity, and placing the pipes closer to the pavement surface. The use of a supply temperature of $10{ }^{\circ} \mathrm{C}$ instead of $15{ }^{\circ} \mathrm{C}$, however, resulted in the increase in solar efficiency by $26 \%$. These results were supported by Mirzanamadi et al. [16]. They studied how different supply temperatures would affect that amount of energy that could be harvested. They varied the supply temperature from $4{ }^{\circ} \mathrm{C}$ to $20{ }^{\circ} \mathrm{C}$ and found that the increase in supply temperatures decreased the amount of harvested energy.

The PSC efficiency has been investigated in different projects. To our knowledge, however, this has not been studied in the Scandinavian context and for a borehole-connected system. This paper presents the measured and calculated harvested energy of a PSC in Sweden. Furthermore, the influence of solar absorptivity, fluid flow rate, and pipe spacing on the amount of harvested energy is investigated.

\section{Measuring harvested energy}

The hydronic heated pavement (HHP) located outside the city of Östersund $\left(63.18^{\circ} \mathrm{N}, 14.5^{\circ} \mathrm{E}\right)$ in Sweden is employed to determine the magnitude of energy harvested by a pavement solar collector. The field station, which has a low traffic volume, is built as part of a test track for trucks. The field station for an HHP is constructed with a concrete top layer with pipes placed at a depth of $62 \mathrm{~mm}$ (pipe centre) and spaced $50 \mathrm{~mm}$ on centres. Concrete is employed to avoid problems related to road paving that can potentially alter the positions of sensors embedded in the pavement. Underneath the top layer, the HHP is prepared as a regular road pavement but with an insulation layer that provides more stable boundary conditions for comparison with numerical simulation results. The pipes are made of cross-linked polyethylene with $20 \times 2-\mathrm{mm}$ dimensions. The 10 parallel pipes laid back and forth in the concrete has a total length of approximately $140 \mathrm{~m}$ and cover an area of $70 \mathrm{~m}^{2}$, as shown in Fig. 1 and Fig. 2. The fluid in the pipes is an ethylene glycol-water mixture with a concentration of approximately $47 \%$. This fluid is selected because of its low freezing point, good heat transfer qualities, and low environmental risks. The HHP is connected to four boreholes that acts as a borehole thermal energy storage (BTES). The

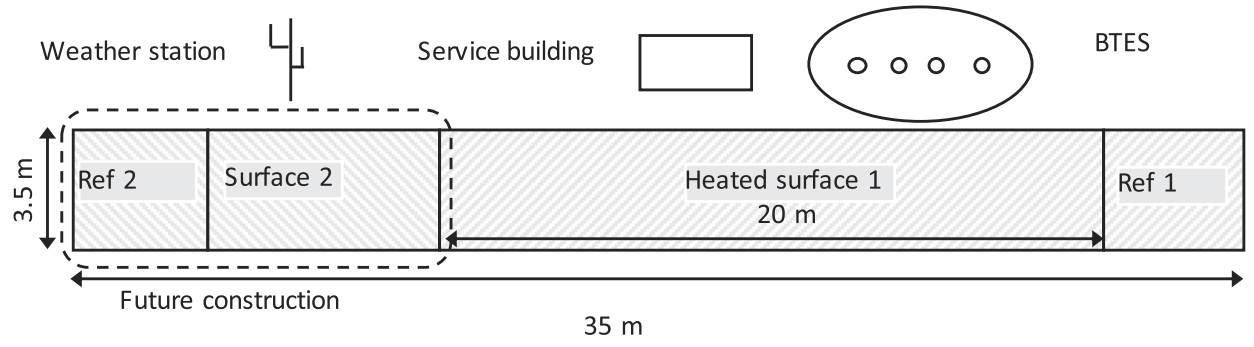

Fig. 2. Main components and layout of the studied field station in Östersund. 


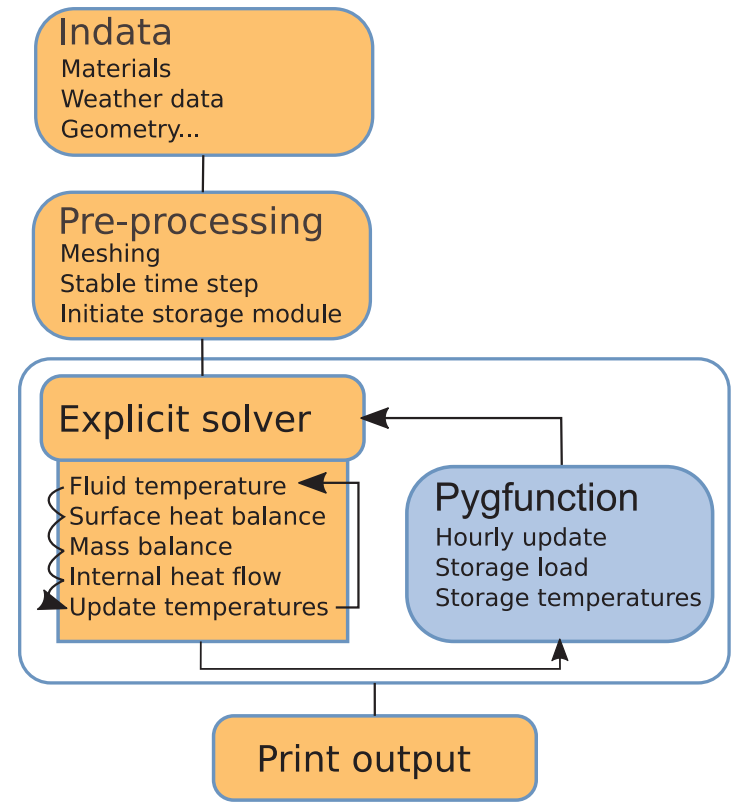

Fig. 3. Flow chart for the simulation tool HyRoSim used in this study.

boreholes are drilled with an equal spacing of $10 \mathrm{~m}$ to a depth of $210 \mathrm{~m}$. According to previous geological surveys, the boreholes are drilled in clay slate covered by an approximately $10 \mathrm{~m}$ of glacial till. In 2018, thermal response tests were performed, and the ground thermal conductivity was determined to be $3.15 \mathrm{~W} / \mathrm{mK}$ with a volumetric thermal capacity of $2.8 \mathrm{MJ} / \mathrm{m}^{3} \mathrm{~K}$ [17].

The harvested energy is determined by measuring the fluid flows and fluid temperatures at the inlet and outlet of the PSC and at the BTES. Furthermore, temperatures within the PSC and the reference surface are measured by PT100 sensors at several positions.

\section{Calculation of harvested energy}

The magnitude of harvested energy is calculated by HyRoSim (a software developed by the authors), which builds on a numerical model for the HHP [11] and a modified numerical borehole storage model Pygfunction [17]. The two models are combined as shown in Fig. 3. The finite difference model (HyRoSim) calculates the pavement and fluid temperatures for each time step, and Pygfunction updates the supply temperatures to the pavement based on the hourly heat load of the storage. It is therefore possible to predict the fluid and pavement temperatures as well as the surface conditions of the system.

The HHP model is developed to calculate the heat flows and surface conditions representing a real HHP system. A sketch of the studied problem and geometrical model of a road with an embedded parallelpipe array is presented in Fig. 4. The upper pavement layer is exposed to the outdoor climate, and the lower boundary could either be adiabatic or have a fixed temperature. The geometrical model consists of several horizontal layers with different thermal properties. In the longitudinal $\mathrm{z}$-direction, the geometrical model is divided into a number of segments $(\mathrm{Seg}$ ), each having the same thermal properties. The model represents a centrally placed pipe in an infinite pipe array. In each segment, the heat transfer from the fluid to the surrounding pavement is calculated by the finite difference method. The thermal connections between subsequent segments (z-direction) are represented by the convective heat transfer in the pipes. Further details regarding the HHP model are found in Johnsson and Adl-Zarrabi [11].

The numerical borehole storage model is a modification of Pygfunction, which is an open-source software package based on the work by Cimmino and Bernier [18] and Cimmino [19]. Pygfunction calculates the fluid and borehole wall temperatures in a borehole field

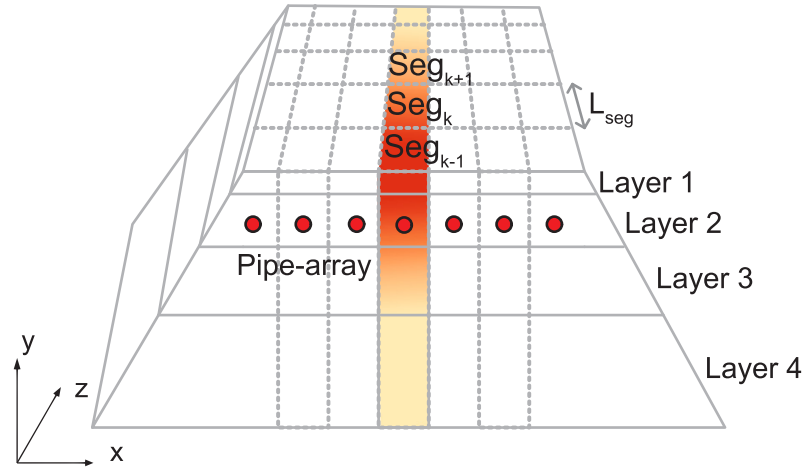

Fig. 4. Hydronic heated pavement divided into segments along the longitudinal fluid flow axis (z). The HHP model represents the centrally shaded volume.

based on the heat load applied to the storage. The modification consists of an implementation a routine to calculate the borehole resistance $\left(R_{b}\right)$ of groundwater-filled boreholes. Pygfunction is modified because groundwater-filled boreholes are common in Scandinavia, and the natural convection within the borehole is a problem in determining $R_{b}$. Natural convection is a result of temperature differences within the borehole and reduces $R_{b}$ as a result of convective heat transfer. Further details on Pygfunction and the methods of calculating $R_{b}$ are found in Johnsson and Adl-Zarrabi [17].

The input data used in the calculation of harvested energy by HyRoSim are summarised in Table 1, and the geometrical dimensions and thermal properties are listed in Table 2. HyRoSim requires surface boundary conditions (weather data), such as air temperature, relative humidity, wind speed, global radiation, cloudiness, and precipitation. The weather data, except for cloudiness and global radiation, are collected at the field station. The cloudiness is collected from the weather forecast of the Swedish Meteorological and Hydrological Institute, and the global radiation is measured at a weather station $10 \mathrm{~km}$ from the test site.

\section{Results and discussion}

The measurements during the summer of 2018 started on the 14th of May and ended on the 31th of August. The summer of 2018 was exceptionally warm with a mean air temperature of $2{ }^{\circ} \mathrm{C}$ above average, thereby increasing the amount of harvested energy. The measured accumulated energy $\left(E_{P S C}\right)$ from the PSC and the heat extraction rate $\left(Q_{P S C}\right)$ are shown in Fig. 5. The heat extraction rate reached a peak value of $20 \mathrm{~kW}$, whereas the daily mean varied between 4 and $10 \mathrm{~kW}$. The total accumulated energy during the period was $17200 \mathrm{kWh}$, which is equivalent to $245 \mathrm{kWh} / \mathrm{m}^{2}$, whereas the total amount of

Table 1

General input parameters for the studied PSC system.

\begin{tabular}{lll}
\hline Parameter & Value & Unit \\
\hline Fluid flow in one pipe & 0.114 & $\mathrm{~L} / \mathrm{s}$ \\
Distance between the pipes & 50 & $\mathrm{~mm}$ \\
Embedded depth (from centre of the pipe to & 62 & $\mathrm{~mm}$ \\
$\quad$ the surface) & 140 & $\mathrm{~m}$ \\
Length of pipe & $0.80,0.85,0.9,0.97$, & - \\
Surface emissivity (dry, moist, wet, frost, ice, & $0.97,0.9$ & \\
$\quad$ snow) & $0.4,0.25,0.2,0.5$, & - \\
Surface albedo (dry, moist, wet, frost, ice, & $0.5,0.9$ & $\mathrm{~kg} / \mathrm{m} 3$ \\
$\quad$ snow) & 1070 & $\mathrm{~J} / \mathrm{kg} \cdot \mathrm{K})$ \\
Density of fluid & 3258 & $\mathrm{~W} /(\mathrm{m} \cdot \mathrm{K})$ \\
Specific heat capacity of fluid & 0.389 & $\mathrm{mPa} \cdot \mathrm{s}$ \\
Thermal conductivity of fluid & 5.88 & - \\
Dynamic viscosity & 12 & $\mathrm{~W}$ \\
AADT-Annual average daily traffic & 500 & \\
Pump power & &
\end{tabular}


Table 2

Materials properties of the construction.

\begin{tabular}{|c|c|c|c|c|c|}
\hline Layer & $\begin{array}{l}\text { Thickness } \\
{[\mathrm{mm}]}\end{array}$ & Material & $\begin{array}{l}\text { Density } \\
{\left[\mathrm{kg} / \mathrm{m}^{3}\right]}\end{array}$ & $\begin{array}{l}\text { Specific heat capacity } \\
{[\mathrm{J} / \mathrm{kg} \cdot \mathrm{K}]}\end{array}$ & $\begin{array}{l}\text { Thermal conductivity } \\
{[\mathrm{W} / \mathrm{mK}]}\end{array}$ \\
\hline Wearing layer & 150 & Concrete C35/45 & 2200 & 900 & 2.17 \\
\hline Pipes & 20 & PE-Xa $20 \times 2 \mathrm{~mm}$ & 925 & 2300 & 0.35 \\
\hline Base layer & 120 & Gravel $0-40 \mathrm{~mm}$ & 2030 & 900 & 0.6 \\
\hline Subbase layer & 400 & Gravel $0-80 \mathrm{~mm}$ & 2000 & 900 & 0.8 \\
\hline Insulation & 100 & XPS 500 & 30 & 1200 & 0.035 \\
\hline Subgrade layer & 5000 & Glacial Till & 1800 & 900 & 1.2 \\
\hline
\end{tabular}

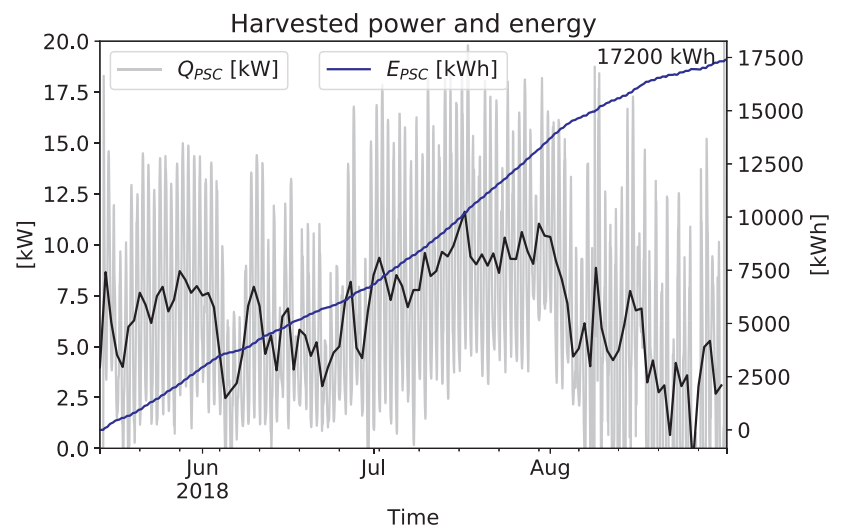

Fig. 5. Power and accumulated energy flow from PSC during summer of 2018. Black line represents the daily mean heat harvest rate.

incoming solar radiation was $614 \mathrm{kWh} / \mathrm{m}^{2}$.

The harvest of energy results in the reduction in the surface temperature of the pavement that could potentially increase the pavement's service life. Compared with the reference surface, the mean temperature reduction during the summer was $6.4{ }^{\circ} \mathrm{C}$, whereas a maximum reduction of $10{ }^{\circ} \mathrm{C}$ was recorded during the month of July (Fig. 6). This temperature reduction increases the service life of the pavement; for some structures, service life can even be increased by 50\% [7].

The fluid and surface temperatures, and the energy harvested by the PSC are calculated using HyRoSim. The calculated results are compared with measured results obtained at the field station.

Fig. 7 shows the daily mean values of surface temperature, return fluid temperature, and accumulated harvested energy. The calculated accumulated energy by HyRoSim is equal to $16962 \mathrm{kWh}$, which indicates good agreement with the $17200 \mathrm{kWh}$ accumulated energy measured at the field station (with a $1 \%$ difference of order).

The calculated surface temperature is $2 \%$ to $8 \%$ higher than the measured surface temperature, as shown in Fig. 6. The deviation between these two results depends on the spatial uncertainty of the embedded temperature sensor in the pavement. There may be a difference

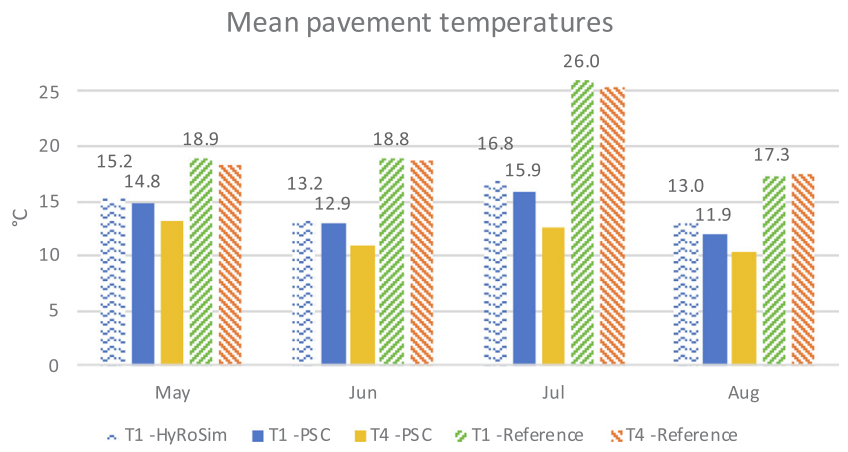

Fig. 6. Daily mean pavement temperatures during the summer of 2018. T1-PSC refers to PSC surface temperature $(5 \mathrm{~mm})$, T4-PSC is located at the bottom of the wearing layer $(150 \mathrm{~mm})$. "Reference" refers to the reference surface.

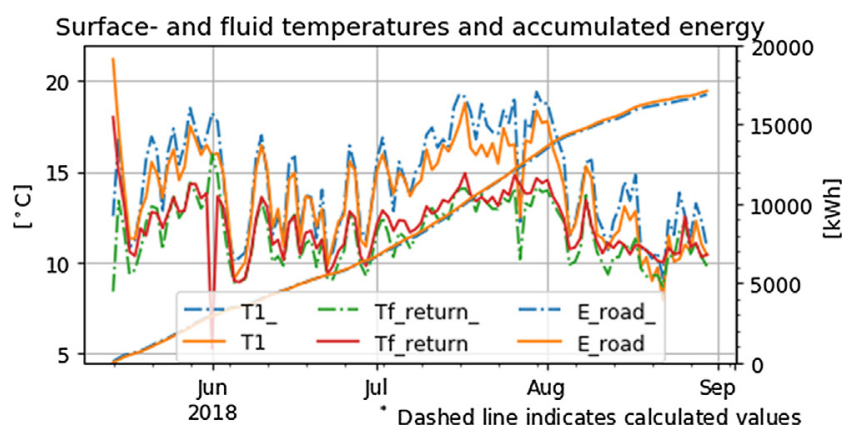

Fig. 7. Daily mean values of calculated and measured, surface temperature, return fluid temperature and harvested energy.

between the design and real positions after the pavement is cast. Considering this uncertainty, the absolute pavement temperature can be assumed accurate with a mean deviation of $0.65{ }^{\circ} \mathrm{C}$. Furthermore, the mean absolute deviation of the return fluid temperature is $-0.54^{\circ} \mathrm{C}$.

Based on the comparison of calculated and measured results, it is found that HyRoSim suitably estimates the performance of a pavement solar collector system.

A lower surface temperature can cause moisture condensation on the surface of the pavement if the surface temperature is lower than the dew-point temperature of ambient air. During the summer of 2018, the conditions for condensation were observed for approximately $400 \mathrm{~h}$. The images captured by the monitoring system at the field station confirm surface condensation (darker colour of PSC in Fig. 8). Surface condensation, which has not been previously reported on the PSC, may, however, pose a risk if sudden temperature changes (below or equal to $0{ }^{\circ} \mathrm{C}$ ) in ambient air causes ice formation at the surface. However, during the measurement period, temperatures were well above the freezing temperature, which prevented ice formation. Furthermore, the moisture condensation process releases latent heat that may stabilise the pavement temperature during night-time. The same amount of energy, however, is necessary for evaporation. The net addition of latent heat from condensation and evaporation may thus be zero.

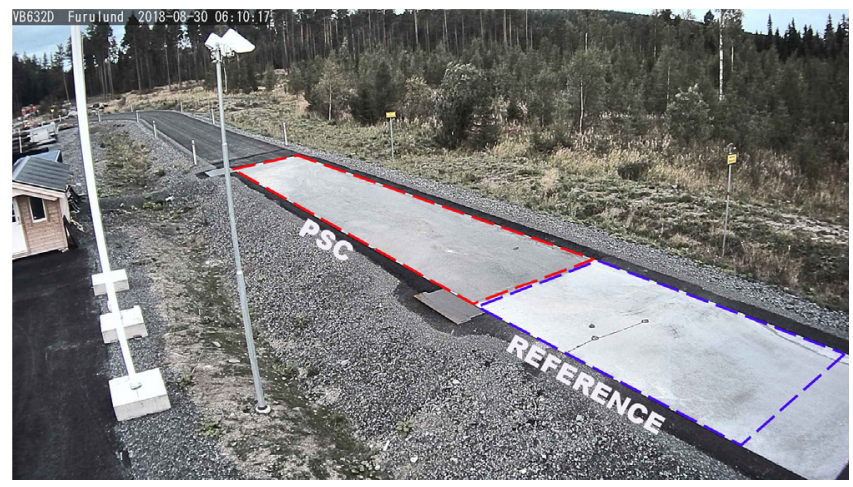

Fig. 8. Condensation of water due to low temperatures on PSC surface. Darker colour on PSC surface indicates moisture. 
The efficiency of the PSC ( $\eta_{P S C}$ ) describes the extent to which solar radiation can be harvested by the PSC. There are various methods for calculating the PSC efficiency [20-23], and most of these are based on instantaneous efficiency [24]. The instantaneous efficiency is recommended for steady-state conditions and $\eta_{P S C}$ is calculated based on hourly values as

$\eta_{P S C}^{h}=\frac{\sum_{t=1}^{\text {hour }} Q_{P S C}}{\sum_{t=1}^{\text {hour }} q_{S w} \cdot A_{P S C}}$

where $Q_{P S C}$ is the heat output from the pavement solar collector, $q_{s w}$ is the incoming short-wave radiation that strikes the pavement surface and $A_{P S C}$ is the surface area of the PSC. This technique of calculating the efficiency, however, creates a problem because of the thermal inertia of the system. When there are a low amounts of incoming short-wave radiation, and pavement temperatures remains high, the efficiency can also become artificially high. To compensate for this artificial high efficiency, the daily efficiency $\left(\eta_{P S C}^{\text {day }}\right)[12,15]$ considers the total amounts of harvested energy and solar radiation in a day, as follows.

$\eta_{P S C}^{d a y}=\frac{\sum_{t=1}^{d a y} Q_{P S C}}{\sum_{t=1}^{d a y} q_{s w} \cdot A_{P S C}}$

Fig. 9b presents the hourly efficiency distribution of the PSC for different times $\eta_{P S C}^{h}$. The artificial high efficiency can be observed in the morning and evening when there are low amounts of incoming solar radiation. At midday, however, the mean solar efficiency is approximately $35 \%$. The variation during the day makes it difficult to determine the specific value of $\eta_{P S C}$. It is evident that the daily efficiency $\left(\eta_{P S C}^{\text {day }}\right)$ is dependent on the amount of incoming solar energy. During sunny days, when the cloudiness is low (0-4 octans), $\eta_{P S C}$ is approximately $40 \%$ (Fig. 9a). When the weather is cloudy (7-8 octans) $\eta_{P S C}^{d a y}$ increases to $60 \%$. This means that when the solar radiation is low, a greater amount of the harvested energy is derived from ambient air. The difference between hourly and daily results makes it difficult to define the efficiency of PSC. To the best of our knowledge, however, the use of daily efficiency $\left(\eta_{P S C}^{d a y}\right)$ is the best approach for comparing different PSC designs. The daily mean value obtained in this study indicates that the solar efficiency is $42 \%$ for the warm summer of 2018 .

\subsection{Influence of albedo}

The potential for a surface to absorb solar energy considerably depends on the surface albedo. Albedo is not constant, and that of pavement surfaces is usually subjected to a time-dependent change. Bitumen-based materials usually becomes lighter in colour as a result of bitumen ageing and wear, whereas concrete pavements tend to become

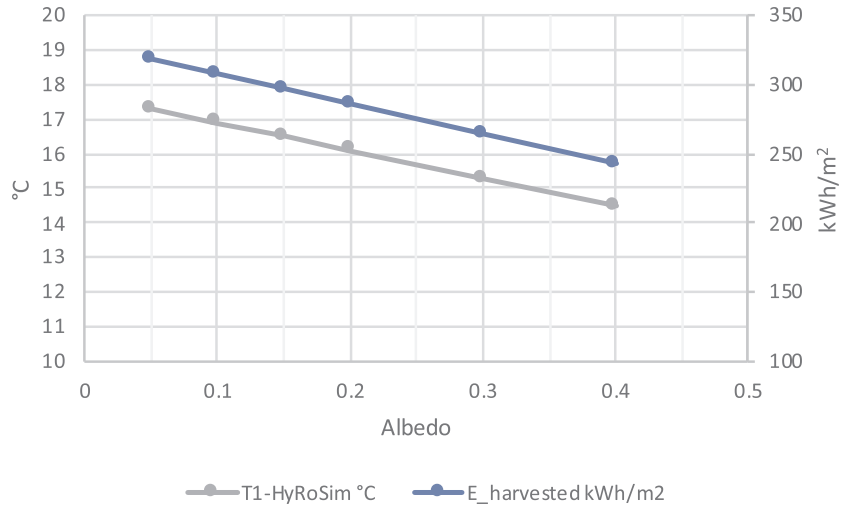

Fig. 10. Calculated mean surface temperature (T1-HyRoSim) and accumulated amount of harvested energy corresponding to different values of albedo on pavement surface.

darker because of particles from traffic [25]. The albedo of concrete pavements commonly varies from 0.4 to 0.25 , whereas that of asphalt pavements varies from 0.05 to 0.20 [25-27].

The amount of energy absorbed by a concrete surface with an albedo of 0.05 to 0.4 is calculated as presented in Fig. 10. The results indicate that by altering the surface albedo from 0.4 to 0.05 , the amount of harvested energy can be increased from approximately $240 \mathrm{kWh} / \mathrm{m}^{2}$ to $320 \mathrm{kWh} / \mathrm{m}^{2}$, i.e., an approximately $30 \%$ increase.

\subsection{Influence of fluid flow}

The fluid flow rate affects the amount of energy that can be harvested. A higher fluid flow rate results in a lower mean temperature of the fluid, which increases heat transfer. If the flow rate is extremely low, then the PSC will not be used efficiently because the temperature difference between the fluid and pavement will be low. A higher flow rate yields a larger temperature difference, which increases the amount of harvested energy and reduces the mean pavement temperature (Fig. 11). An increase of fluid flow from $0.02 \mathrm{~L} / \mathrm{s}$ to $0.17 \mathrm{~L} / \mathrm{s}$ leads to an increase in harvested energy from $140 \mathrm{kWh} / \mathrm{m}^{2}$ to $280 \mathrm{kWh} / \mathrm{m}^{2}$. An increase of the fluid flow, however, requires an increase in electrical energy to drive the pumps. The fluid flow rate should thus be optimised.

\subsection{Influence of pipe distance}

The position of the embedded pipes in the pavement has a major influence on the amount of collected energy. Generally, a shallower position and a shorter distance between pipes will lead to a higher

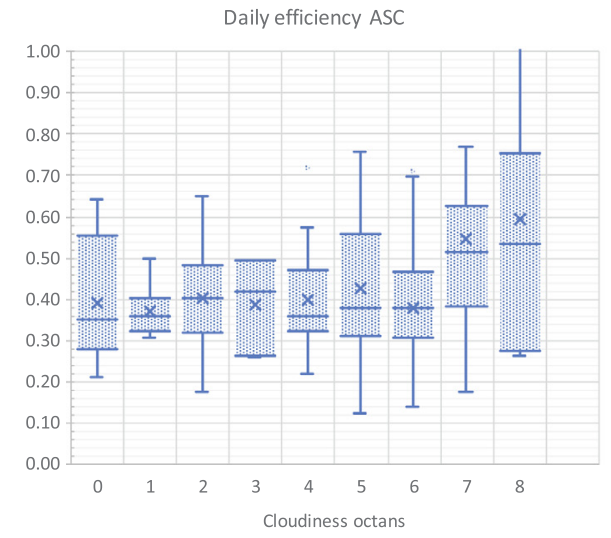

(a) Daily efficiency of the PSC $\left(\eta_{P S C}^{\text {day }}\right)$, depending on cloudiness.

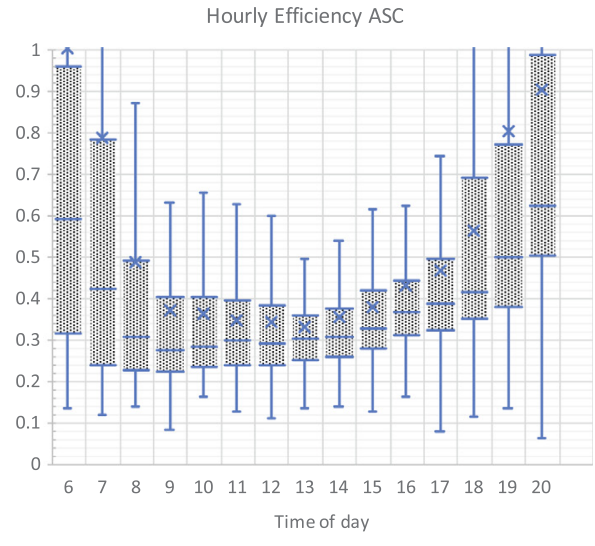

(b) Hourly efficiency of the PSC $\left(\eta_{P S C}^{h}\right)$.
Fig. 9. Efficiency of the PSC $\left(\eta_{P S C}\right)$ during the summer of 2018. 


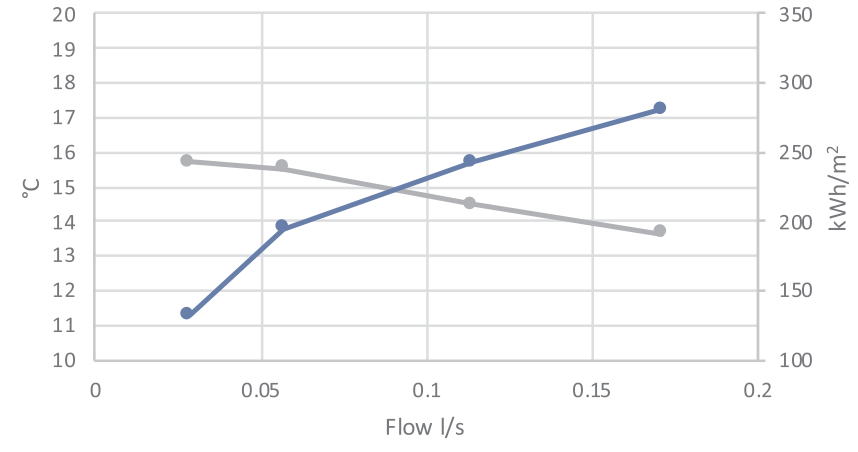

-T1-HyRoSim ${ }^{\circ} \mathrm{C} \longrightarrow$ E_harvested kWh/m2

Fig. 11. Calculated mean surface temperature (T1-HyRoSim) and accumulated amount of harvested energy at different flow rates.

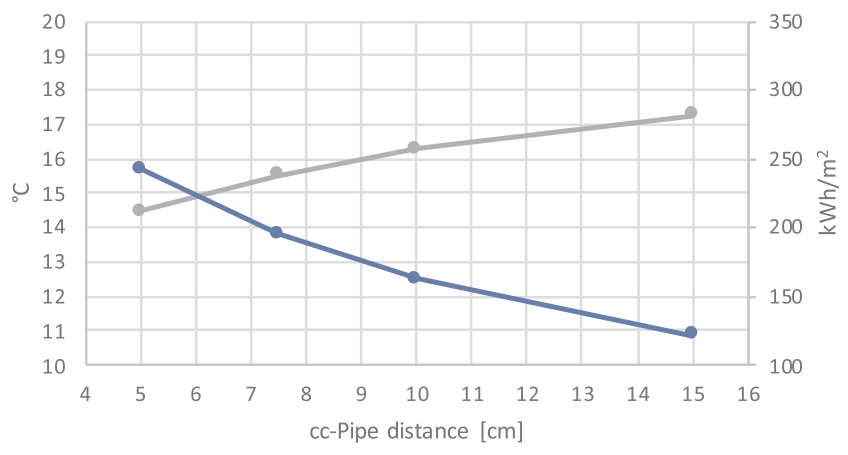

-T1-HyRoSim ${ }^{\circ} \mathrm{C} \longrightarrow \mathrm{E}_{-}$harvested kWh/m2

Fig. 12. Calculated mean surface temperature (T1-HyRoSim) and cumulative amount of harvested energy with different pipe centre to centre spacings.

amount of harvested energy. The periodic maintenance activities of a pavement restrict the shallowest position of a pipe system to a depth of 5-7 $\mathrm{cm}$ below the pavement surface. The centre to centre $(c c)$ spacing between adjacent pipes, however, can be reduced. The influence of pipe spacing is investigated by calculating the harvested energy when the distance between pipes is $5 \mathrm{~cm}$ to $15 \mathrm{~cm}$. The calculation results are presented in Fig. 12.

The calculated amount of harvested energy are $250 \mathrm{kWh} / \mathrm{m}^{2}$ and $120 \mathrm{kWh} / \mathrm{m}^{2}$ when the spacing between pipes are 5 and $15 \mathrm{~cm}$, respectively, i.e., a pipe spacing that is three times closer leads to a $100 \%$ higher amount of harvested energy. However, there are other limiting factors, when placing the pipes close to each other. For example, the bending radius of pipes cannot be overly short because it may damage the pipes. Furthermore, the load-bearing capacity of the pavement may be reduced if numerous pipes are embedded.

\subsection{Parameter sensitivity}

The influences of the three investigated parameters are combined, and the daily efficiency $\left(\eta_{P S C}^{d a y}\right)$ is calculated. The reference system refers to the parameter values used during the experiments in the summer of 2018. By reducing the albedo, the efficiency increases from $42 \%$ (reference system) to $49 \%$, as shown in Fig. 13. The albedo, however, should be reduced by $50 \%$. Increasing the pipe spacing by $50 \%$ leads to decrease in efficiency from $42 \%$ to $34 \%$. A $50 \%$ fluid flow increase yields an efficiency of $49 \%$.

The system efficiency can be increased to $49 \%$ (from $42 \%$ ) either by changing the fluid flow rate or albedo by $50 \%$. Comparing the efficiency of the PSC presented in Fig. 13 with previously reported efficiencies of $30 \%$ [12] and $15 \%$ to $20 \%$ [15], the efficiency reported in this study is clearly greater. This may be because Guldentops et al. [15]

\section{Parameter sensitivity}

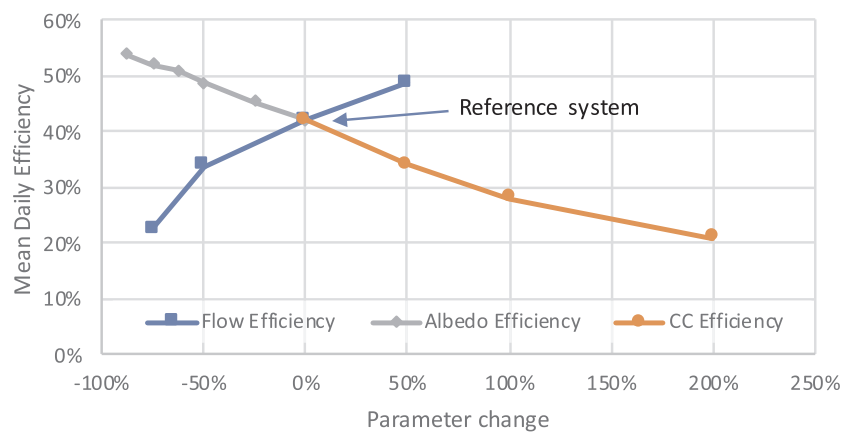

Fig. 13. Calculated mean values of daily efficiency at different variations of fluid flow, albedo, and pipe distance.

used a considerably lower flow rate and a pipe spacing of $15 \mathrm{~cm}$, which is twice more than that utilised in this study. On the other hand, the higher efficiency obtained by Loomans et al. [12] is possibly because they used a spacing of $15 \mathrm{~cm}$ but with an albedo of 0.2 and a lower supply temperature of $10{ }^{\circ} \mathrm{C}$. It can be thus be concluded that the simulations and measurement performed in this study are in line with those of previously reported investigations.

\section{Conclusion}

The influences of pipe spacing, fluid flow rate, and albedo on the performance of a pavement solar collector are determined by using the developed software, HyRoSim. The calculated results are compared with the measured results obtained from a field station in Sweden.

The measured harvested energy during the summer of 2018 is $245 \mathrm{kWh} / \mathrm{m}^{2}$. Energy harvesting from the pavement leads to a mean surface temperature reduction of $6.4{ }^{\circ} \mathrm{C}$ compared with the reference surface. The maximum surface temperature decrease of $10{ }^{\circ} \mathrm{C}$ was observed in July 2018.

A reduced surface temperature can extend the service life of a pavement. When the temperature of the surface is lower than that of ambient air, however, this may result in moisture condensation on the surface. To our knowledge, the condensation caused by the usage of PSC has not been reported in previous works. The condensation can cause a limited risk of ice formation on the surface as a result of the sudden surface change from dry to wet combined with freezing temperatures.

The calculated $42 \%$ solar efficiency of the PSC during the summer of 2018 is higher than those in the other studies. The higher efficiency of the field station in Sweden can be explained by the short pipe spacing of $5 \mathrm{~cm}$, high fluid flow rate, and low supply temperature.

The influences of pipe spacing, fluid flow rate, and albedo on the performance of a pavement solar collector are studied. A 50\% higher fluid flow rate or $50 \%$ reduction in albedo leads to an efficiency of $49 \%$ compared to the aforementioned $42 \%$ efficiency.

The high efficiency exhibited by the studied system makes the utilisation of pavement solar collectors advantageous for low-temperature applications. These include space heating systems (e.g., recharging shallow geothermal boreholes with solar energy during summer), which can thereby enhance the efficiency of ground source heat pump systems during winter.

\section{CRediT authorship contribution statement}

Josef Johnsson: Writing - original draft. Bijan Adl-Zarrabi: Writing - review \& editing. 


\section{Declaration of Competing Interest}

The authors declare that they have no known competing financial interests or personal relationships that could have appeared to influence the work reported in this paper.

\section{Acknowledgements}

The field station used in this study is part of the NordFoU project, HERO, funded by the Swedish Transport Administration (Trafikverket). The utilised boreholes are funded by GEOTEC. The financial support for the main author is provided by the Norwegian Public Road Administration (Statens Vegvesen) through the Coastal Highway E39 project.

\section{Appendix A. Supplementary material}

Supplementary data associated with this article can be found, in the online version, at https://doi.org/10.1016/j.apenergy.2019.114286.

\section{References}

[1] IEA. Energy Technology Perspectives 2017. IEA, Paris; 2017. http://www.oecd ilibrary.org/energy/energy-technology-perspectives-2017_energy_tech-2017-en. doi: 10.1787/energy_tech-2017-en, arXiv:IEA, 2016.

[2] Dezfooli AS, Nejad FM, Zakeri H, Kazemifard S. Solar pavement: a new emerging technology. Sol Energy 2017;149:272-84. https://doi.org/10.1016/j.solener.2017. 04.016http://linkinghub.elsevier.com/retrieve/pii/S0038092X17303018.

[3] Papagiannakis A, Dessouky S, Montoya A, Roshani H. Energy harvesting from roadways. Procedia Comput Sci 2016;83:758-65. https://doi.org/10.1016/j.procs. 2016.04.164https://linkinghub.elsevier.com/retrieve/pii/S1877050916301971.

[4] Tahami SA, Gholikhani M, Nasouri R, Dessouky S, Papagiannakis AT. Developing a new thermoelectric approach for energy harvesting from asphalt pavements. Appl Energy 2019;238:786-95. https://doi.org/10.1016/j.apenergy.2019.01.152.

[5] Ahmad S, Abdul Mujeebu M, Farooqi MA. Energy harvesting from pavements and roadways: a comprehensive review of technologies, materials, and challenges. Int $J$ Energy Res 2019:1-42http://doi.wiley.com/10.1002/er.4350.

[6] Bobes-Jesus V, Pascual-Muñoz P, Castro-Fresno D, Rodriguez-Hernandez J. Asphalt solar collectors: a literature review. Appl Energy 2013;102:962-70. https://doi.org/ 10.1016/j.apenergy.2012.08.050.

[7] Ebrahim Abu El-Maaty A. Temperature change implications for flexible pavement performance and life. Int J Transp Eng Technol 2018;3:1. https://doi.org/10. 11648/j.ijtet.20170301.11.

[8] Dehdezi PK. Impact of concrete thermophysical properties on pavement structural design. J Mater Civ Eng 2014;26:4014018. https://doi.org/10.1061/(asce)mt.19435533.0000978.

[9] Nasir DS, Hughes BR, Calautit JK. Influence of urban form on the performance of road pavement solar collector system: Symmetrical and asymmetrical heights. Energy Convers Manage 2017. https://doi.org/10.1016/j.enconman.2017.03. 081http://www.sciencedirect.com/science/article/pii/S0196890417302923.

[10] Johnsson J. Winter Road Maintenance using Renewable Thermal Energy [Ph.D thesis]. Gothenburg: Chalmers University of Technology; 2017. http://publications. lib.chalmers.se/publication/248119-winter-road-maintenance-using-renewablethermal-energy.

[11] Johnsson J, Adl-Zarrabi B. Modeling the thermal performance of low temperature hydronic heated pavements. Cold Reg Sci Technol 2019;161:81-90. https://doi. org/10.1016/j.coldregions.2019.03.007https://linkinghub.elsevier.com/retrieve/
pii/S0165232X18303641.

[12] Loomans M, Oversloot H, de Bondt A. Design tool for the thermal energy potential of asphalt pavements. Eighth international IBPSA conference, Eindhoven, Netherlands. 2003. p. 745-52http://www.ibpsa.org/\%5Cproceedings \%5CBS2003\%5CBS03_0745_752.pdf.

[13] Adl-Zarrabi B, Ebrahimi B, Hoseini M, Johnsson J, Mirzanamadi R, Taljegard M Safe and sustainable coastal highway route E39. Transp Res Procedia 2016;14:3350-9. https://doi.org/10.1016/j.trpro.2016.05.286http://linkinghub. elsevier.com/retrieve/pii/S2352146516302927.

[14] Baetens R, Severins I, Ceulemans D, Arimilli S, Couscheir K, Jacobs G, et al. The exploration of the use of a heat exchanging asphalt layer as a prosumer in a low temperature heating grid. REHVA annual meeting conference low carbon technol ogies in HVAC. 2018. p. 1-8.

[15] Guldentops G, Nejad AM, Vuye C, Van den bergh W, Rahbar N. Performance of a pavement solar energy collector: Model development and validation. Appl Energy 2016;163:180-9. URL https://doi.org/10.1016/j.apenergy.2015.11.010 http:// www.scopus.com/inward/record.url?eid $=2$-s2.0-84947918366\& partnerID = tZOtx3y1, doi: 10.1016/j.apenergy.2015.11.010.

[16] Mirzanamadi R, Hagentoft CE, Johansson P. Numerical investigation of harvesting solar energy and anti-icing road surfaces using a hydronic heating pavement and borehole thermal energy storage. Energies 2018;11:3443. https://doi.org/10.3390/ en11123443http://www.mdpi.com/1996-1073/11/12/3443.

[17] Johnsson J, Adl-Zarrabi B. Modelling and evaluation of groundwater filled boreholes subjected to natural convection. Appl Energy 2019;253:113555. https://doi. org/10.1016/j.apenergy.2019.113555.

[18] Cimmino M, Bernier M. A semi-analytical method to generate g-functions for geothermal bore fields. Int J Heat Mass Transf 2014;70:641-50. https://doi.org/10. 1016/j.ijheatmasstransfer.2013.11.037.

[19] Cimmino M. A finite line source simulation model for geothermal systems with series- and parallel-connected boreholes and independent fluid loops. J Build Perform Simul 2017:1-19. https://doi.org/10.1080/19401493.2017.1381993.

[20] Gao Q, Huang Y, Li M, Liu Y, Yan YY. Experimental study of slab solar collection on the hydronic system of road. Sol Energy 2010;84:2096-102. https://doi.org/10. 1016/j.solener.2010.09.008.

[21] Shaopeng W, Mingyu C, Jizhe Z. Laboratory investigation into thermal response of asphalt pavements as solar collector by application of small-scale slabs. Appl Therm Eng 2011;31:1582-7. http://www.sciencedirect.com/science/article/pii/ S1359431111000378 http://www.scopus.com/inward/record.url?eid=2-s2.0 79954437296\&partnerID $=40 \& \mathrm{md} 5=9819 \mathrm{~d} 79 \mathrm{e} 9 \mathrm{db} 95891 \mathrm{c5c} 60 \mathrm{ff} 56 \mathrm{~b} 4 \mathrm{ae} 8 \mathrm{~b} 9$ https://linkinghub.elsevier.com/retrieve/pii/S1359431111000378, doi:10.1016/j. applthermaleng.2011.01.028.

[22] Zhou Z, Hu S, Zhang X, Zuo J. Characteristics and application of road absorbing solar energy. Front Energy 2013;7:525-34. https://doi.org/10.1007/s11708-013 0278-2http://link.springer.com/10.1007/s11708-013-0278-2.

[23] Zhou Z, Wang X, Zhang X, Chen G, Zuo J, Pullen S. Effectiveness of pavement-solar energy system - an experimental study. Appl Energy 2015;138:1-10. https://doi. org/10.1016/j.apenergy.2014.10.045http://www.scopus.com/inward/record.url? eid $=2$-s2.0-84909979511\&partnerID $=40 \&$ md5 $=$ dc0b77ddd6852ea2f0fa32de61327a2b.

[24] Duffie JA, Beckman WA. Solar engineering of thermal processes. Hoboken, NJ, USA: John Wiley \& Sons Inc; 2013. https://doi.org/10.1002/9781118671603. arXiv:arXiv:1011.1669v3.

[25] U.S Environmental Protection Agency. Cool Pavements. In: Reducing Urban Heat Islands: Compendium of Strategies; 2012. p. 1-23. https://www.epa.gov/heatislands/heat-island-compendium, doi: 10.1175/1520-0450(2002) $041<0792$ :THFIUA > 2.0.CO; 2

[26] Jansson C, Almkvist E, Jansson PE. Heat balance of an asphalt surface: observations and physically-based simulations. Meteorol Appl 2006;13:203-12. https://doi.org/ 10.1017/S1350482706002179.

[27] Li H, Harvey J, Kendall A. Field measurement of albedo for different land cover materials and effects on thermal performance. Build Environ 2013;59:536-46. https://doi.org/10.1016/j.buildenv.2012.10.014. 